\title{
TRAINING THEORY-INTERACTIVE STRATEGIES IN THE EDUCATIONAL PROCESS
}

\author{
Gabriela CERCHEZ ${ }^{a *}$, Dan Ionuț PETRE ${ }^{b}$, Răzvan Ioan NEDELCU $^{c}$ \\ ${ }^{a}$ Ion Creangă State Pedagogical University of Chișinău, Republic of Moldova \\ ${ }^{b, c}$ State University of Physical Education and Sport, Chișinău, Republic of Moldova
}

\begin{abstract}
In this paper we aim to analyse the extent to which the strategies used in online teaching influence students' learning. As a result, we wish to provide an image on the importance of how to approach teaching strategies that can influence the degree of understanding and learning of notions taught online and what are their advantages and disadvantages, given that online schooling is a completely different environment from physical school. The novelty of the paper is that it capitalizes on the strategy of learning through cooperation in online instructional and educational activities and adapting effective methods, especially in current conditions, when in today's society there is a strong evolutionary process that requires all social categories to keep up, including education. Online training is difficult to practice in the classroom. In the concrete conditions that our society makes available to the teaching process, teachers are aware of both the obvious virtues of the new approach in student education and the difficulties of its application in the classroom, especially in the online environment. The current context has shown that the digitization of the educational system involves more than adapting to a technological context. Digital pedagogy is not a simple material in pdf format presented on the screen, but a much more complex notion. Thus, we can conclude that online learning technology can play an important role in education, it can influence and generate in the future a new paradigm, as an integral part of the educational system.
\end{abstract}

KEYWORDS: education, learning, method, strategy, theory.

DOI: 10.24818/IMC/2021/05.16

\section{INTRODUCTION}

In the current context, worldwide, over 185 states are at different points of SARS-CoV-2 infection rates. Education in these countries has been directly affected. Schools have been determined to close because of the situation pandemics, so that more than 1.5 billion students in these countries were forced to learn online. Romania also belongs to their category, which had to adopt a new teaching system, the teachers and students being put in new situations to approach the lessons. It is clear that this pandemic has completely disrupted an education system that many say has already lost its relevance.

While some theorists are concerned about the hasty nature of the transition from traditional to online teaching, other theorists are convinced that e-learning must become part of the "new normal" as a result of experimenting with this new method of learning. The transition to online learning could be the catalyst for creating a new more effective method of educating students, by developing skills, critical thinking, but also adaptability in various situations, which will be more important for their success in the future. However, the effectiveness of online learning varies by age group. The general consensus of theorists on children, especially those in preschool and primary education, is

\footnotetext{
* Corresponding author. E-mail address: phdeducation@upsc.md
} 
that a structured environment is needed, because at this age children are easily distracted from learning activities.

To get the full benefit of online learning, there must be an effort focused on modern teachinglearning-assessment strategies and methods, using a series of tools as well as teaching techniques that take these aspects into account. The problems are related to a rethinking of the subject, to the teaching methods, to the teachers' education, but also to the evaluation of the students. In this sense, in this paper, the authors aim to analyse the extent to which the teaching strategies approached in online teaching influence learning, starting from the following questions: How is student learning and performance influenced by unplanned and rapid transition to online learning - without prior training and preparation of teachers? What are the effective strategies and methods in online teaching? To what extent can online learning technology play a role in learning?

The present paper focused on verifying the general hypothesis: If e-learning technology can play an important role in education, can it generate a new hybrid model in the future as part of school education?

As a result, the aim of this paper is to provide an image on the importance of how to approach teaching strategies that can influence the degree of understanding and learning of notions taught online and what are their advantages and disadvantages, given that online schooling is a completely different environment from physical school. The novelty of the paper is to capitalize on the strategy of learning through cooperation in online instructional and educational activities and adapting effective methods for the online environment, especially in current conditions, when in today's society there is a strong evolutionary process that requires all social categories to keep step, including education. In order to achieve the general goal, we first resort to the theoretical clarification of learning and the notion of didactic strategy, then we will focus on learning through cooperation with students, and finally to propose some solutions to make this method more efficient.

\section{INTERACTIVE TEACHING STRATEGIES IN THE EDUCATIONAL PROCESS}

\subsection{School learning-peculiarities}

From the beginning we must specify that the main purpose of the educational process is to determine the formation of skills through learning, the latter being a very complex and difficult process. It is very true that "no one learns yet at the required level, intensity and speed, but faces the complexity of the modern world" (Lewis, 2016, p.67), but learning generates knowledge accumulation and skills development. Learning as a complex, dynamic, multilateral phenomenon has a rich content and a wide scope. That is why it is necessary to detach the two essential meanings of the notion of learning: The extensive meaning of learning "learning is any new acquisition of behaviour, as a result of the exercise meant to satisfy the adaptation to the environment" (Cucos,, 2002, p.138).The restrictive meaning of learning, as school learning, respectively the fact that it is realized within the instructive-educational process. Human learning is governed by principles whose achievement gives it efficiency and soundness. According to Stephenson et al., (2008, p.78) In Brain friendly teaching - reducing student's cognitive load there are presented other types of learning such as: maintenance learning (craft type, to maintain the level of performance of the teacher); learning through shock-crises, dramas, shocks that catalyse learning, leading to progress (example: the energy crisis determines the search for other unconventional energy sources) (Lewis, 2016, p.89). The tragedy of space shuttles has propelled technology to overcome barriers and eliminate the so-called risks taken by the pioneers of human progress (McGee, 2014, p.90). Another type of learning is innovative and anticipatory learning, by predicting the future, by avoiding traumatic and creative shocks and continuous performance.

What we must remember from the above is that learning, as a complex mental activity, is based on a series of complicated neurodynamic and neuropsychic mechanisms, whose knowledge is important 
for organizing the instructional-educational process. Without going into details, we mention that these are: neurophysiological mechanisms, neurochemical mechanisms and bioelectrical mechanisms.

\subsection{The concept of interactive teaching strategy}

The didactic strategy represents a set of procedures through which the collaboration between teacher and students is realized in order to teach and learn a volume of information, the formation of skills and habits, the development of the human personality (Nicola, 2003, p.441) or a set of actions and operations of teaching and learning, deliberately structured or programmed, oriented in the direction of achieving, in conditions of maximum effectiveness, the predetermined objectives (Cerghit, 2008, p.329).

Regardless of the definition given by specialists, the teaching strategy is the way in which the teacher achieves the goals he has set, collaborates with students, and activates them to work together, to learn effectively. This must always be considered because students' activism and reporting to their needs and interests fully contribute to building their own understanding.

Interactive teaching strategies emphasize group / team work to find solutions or alternatives to different problems addressed, mutual support, effort, tolerance, acceptance of peers' opinions, development of self-assessment. The key phrase is active interaction, which involves effective relationships and communication between educational actors: teacher-student, student-student. It promotes both face-to-face interactivity and inter and intragroup relations. To achieve this, the teacher needs certain managerial, organizational, communicative skills, etc.

Given that we are talking about interactive teaching strategies, we must mention that the teacher must emphasize, in addition to many other aspects (e.g. thorough preparation of study material), and differentiated learning, the design of trajectories according to the needs of students.

Interactive teaching strategies emphasize socialization and social interaction, being the most important factors in learning and human development. The teacher acts as a mediator and facilitator of learning. He is the one who chooses the strategy, he puts it into practice, but he leaves the students the freedom to choose, to get involved in the activity, he is careful with whoever learns, he puts the student at the centre. The emphasis is on learning, not on teaching, on the active construction of knowledge.

Therefore, we notice that the success of the instructive-educational activity depends to a large extent on the didactic strategy used. The teacher must consider, rather, the motivation of the students to learn and then the content, that is, what he teaches.

Cooperative learning is a method by which students work together to solve a problem, carry out an activity, work in pairs or small groups, but also a pedagogical strategy that encourages students to work together in microgroups to achieve a common goal. (Oprea, 2008, p. 147)

Research results show that students who have the opportunity to work cooperatively learn faster and more efficiently, they feel better in learning activities.

Johnson D.W. and Johnson R.T. (Oprea, 2008, p.147) in a study conducted in 1989, investigates 193 cases comparing the different effects of cooperative learning compared to so-called traditional learning techniques. Only in $10 \%$ of cases, the results of individual methods were more effective. Teamwork develops students' ability to work together - an important skill for the life and work of future citizens.

The main methods used in cooperative learning were grouped into four perspectives by Brigitte Larocque (1995 apud Oprea 2008, pp.74-78). Conceptual perspective refers to the studies carried out by the Johnson brothers and their colleagues from Minnesota, who developed a conceptual school and propose as synonyms of cooperation phrases such as: learning together or circular learning. This perspective is structured on a humanistic vision. of education. She is concerned with the development of each student's potential, with his social and cognitive development. 
Cooperative learning trains young people for life after school and this in a way that is more appropriate and more adapted to modern social realities. It is closely related to students' desire to engage in further social interactions. Structural perspective includes studies by Spencer Kagan and focuses, like the previous one, on social skills. Teachers are advised to use simple structures at the beginning, which they can later combine with others to teach more complex verbal interactions in the team. Kagan indicates the following cognitive skills facilitated by cooperative learning, connecting concepts, generalizing ideas, analysing, and developing general rules, categorizing, asking questions, developing answers. For example, instead of asking a whole class question and waiting for an individualized answer, Kagan proposes a structure called Several heads together. After announcing a question or a topic to be solved the class is divided into teams working together to solve the problem. Then the teacher, who has previously given a number to each team, formulates the question and asks a certain number to answer. This gives more strength to the group, encouraging students to share responsibilities and that their numbers could be drawn, and they want their team to make a good choice.

The curricular perspective proposed by Robert Slavin and his colleagues at the Research Center for Elementary and Middle Schools at Johns Hopkins University has been developed for very heterogeneous classes. Group work has positive effects on interethnic relations and on students with learning disabilities integrated into normal classrooms. This perspective releases the necessary time that the teacher can allocate to the individual needs of each one

For example, students with learning disabilities integrated into normal (mainstream) schools are often less popular because their performance affects team performance, and they may not always benefit from the effects of cooperative learning. Thus, the TAI (Team Accelerated Instruction) method combines individualized teaching and cooperative learning for mastering mathematics in highly heterogeneous classes from an academic point of view. Students working at their own pace are encouraged to help and contribute to team performance.

Shlomo and Yael Sharan, together with Rachel Hertz-Lazarovitz (1979), conceived in Israel the method of investigation, inspired by the work of J. Dewey, which envisaged the establishment of democratic principles in the classroom. This method provides that students group together, according to their interests, to investigate a topic. Also, a topic is divided into several topics that are divided into groups. Each group plans its own autonomous and democratic investigative approach. This method encourages students actively engaged in their learning and considers their interests, which encourages their motivation. The central concept of this perspective is the active participation of students in their own learning, because each has a well-defined role being organized in small aggregates (systems) of students, as interactive units.

In conclusion, these perspectives propose various pedagogical formulas for specific or generic contents, relying on group work, on the mutual help between students or on the participation of students in their own learning.

We must also mention that cooperative learning is based on the following principles (Oprea, 2008, pp. 151-152):

a) Positive interdependence, according to which the success of the group depends on the effort made by all members.

b) Individual responsibility, which refers to the fact that each member of the group assumes responsibility for the task to be solved.

c) The formation and development of social skills, the stimulation of interpersonal intelligence which refers to the ability to communicate with the other, to receive support when you need it, to offer help, to the ability to revolve conflict situations. Students are taught, helped, monitored in the use of collaborative social skills that increase the efficiency of group work.

d) Face-to-face interaction that involves direct contact with the work partner, arranging chairs in the classroom so that small interaction groups can be created in which students can encourage and help each other. 
e) Dividing tasks into groups and reflecting on how tasks will be solved by each member and by the team.

Learning through cooperation respects the principles of egalitarianism, anti-hierarchy and authoritarianism, as well as tolerance of the opinions of others and the avoidance of labelling.

\section{ASPECTS OF ONLINE LEARNING}

\subsection{Teaching-learning in the online environment in the context of the Covid-19 pandemic}

The year 2020 has been a challenging one for all areas. Even education has suffered, given the pandemic context with which the whole of humanity has been provoked. The suspension of face-toface courses and their relocation to the online environment has led to the reorientation of teachers, parents and students to new communication and cooperation practices that ensure continuity of learning.

However, the efforts to carry out educational activities using digital tools and resources are not new, for most teachers because the Ministry of Education and Research has recently promoted programs with digital component, starting with the Computerized Education System (SEI program), the eTwinning action, teacher training programs in the use of new technologies and ending with attempts to build an open educational resource base or the ROSE and CRED projects.

However, the major pressure on the education system in general and on teachers has been the exclusive use of distance media for conducting instructional and educational activities. The Romanian education system was only partially prepared for digital training, the curriculum allows in a variable / sequential / revised transposition into distance activities, and edtech companies were not stimulated to build interoperable solutions, tailored to the needs of the education system.

Despite these shortcomings, the critical period has largely been overcome, teachers, parents and students have adapted to the new conditions imposed by the pandemic, at present, online education is part of the daily lives of students.

Online cooperative learning is, in the current context, a challenge for teachers and students, and at the same time an essential tool for the future of the educational process. It is an interactive strategy that practically motivates students, captures their attention, makes them responsible and helps them develop their personality and social skills, the courage to make decisions and resolve crisis situations, gives them self-confidence, and helps them to and develop emotional skills (Tsay \& Brady, 2010, p.80).

Online education cannot be deprived of interactive teaching and learning. Although it includes an essential change with a new pedagogy based on the use of digital educational platforms and interactivity through the exchange of information from teacher to student and from student to student, it focuses mainly on student-cantered, thus clearly improving, the quality of online teaching-learning. It is essential to capitalize on this interactive strategy, to use methods that facilitate effective learning and understanding of new knowledge and skills. Thus, it is necessary to follow the adaptation for the online environment of the teaching methods of the educational contents, having as priority the concentration on the types of acquisitions and the verification of their acquisition through the summative evaluation of the new knowledge.

In this process of adapting teaching methods to the online environment, the design of a lesson must include: designing and building the learning objectives that the teacher pursues, respectively reflecting the knowledge and skills that students must acquire at the end of the lesson; evaluation (by what methods I evaluate students' acquisitions); recovery or development of synchronous or asynchronous recovery methods and procedures, adapted to the individual needs of each student as a result of the feedback received following the evaluation (Yong, 2005, p.105). 


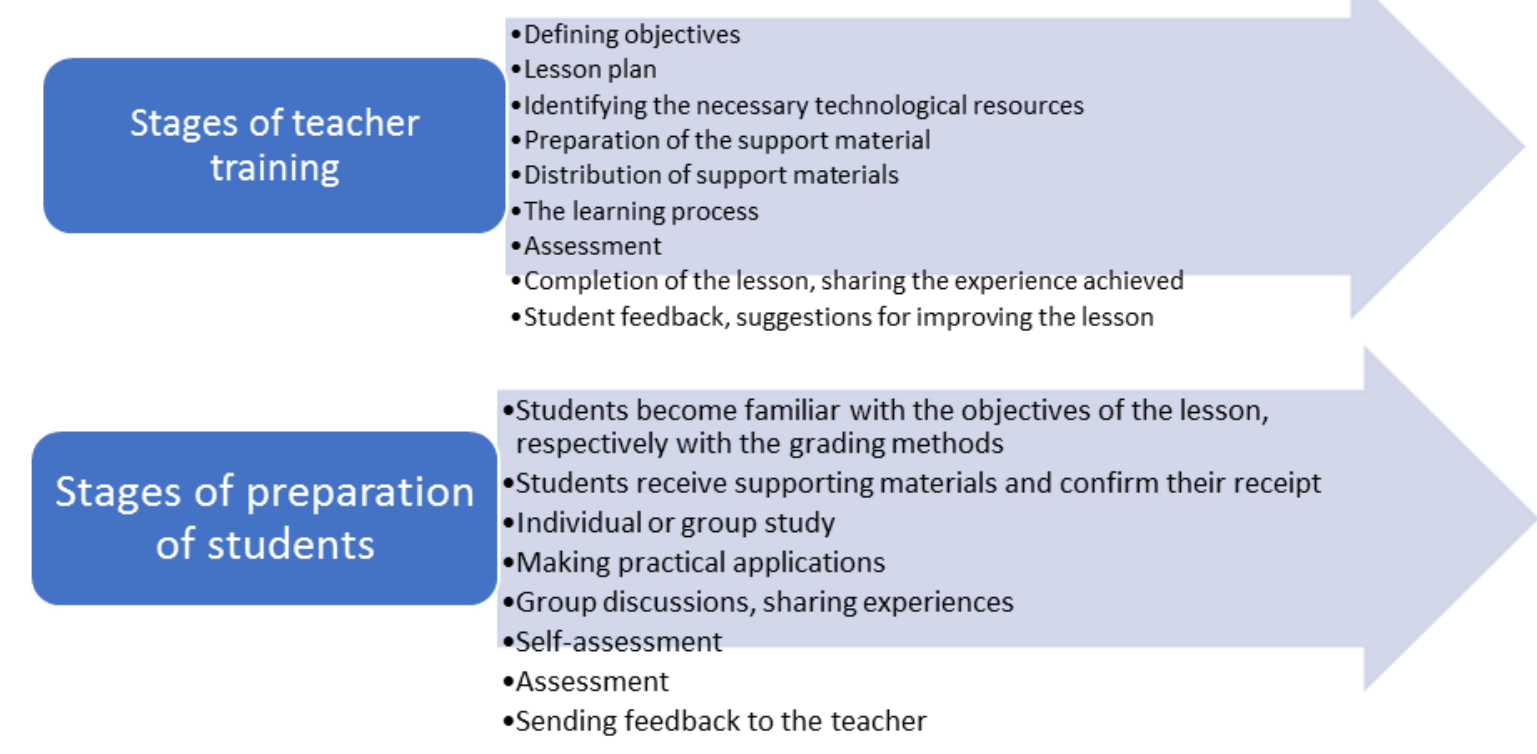

Figure 1. The workflow of the online learning environment Source: adapted from Yong (2005, p.106)

This workflow highlights the interaction with the class, the group of students and the teacher and has an obvious dynamic towards learning, followed by self-assessment, after all tasks have been completed. Depending on the progress of the whole group, supportive learning can help the group of students. Therefore, from the above we can conclude that learning through online cooperation allows a direct approach to the actual educational activities of learning, which consists in involving students so that they can collaborate in the virtual environment, by motivating, involving, and empowering them. The specificity of interactive methods is that they can stimulate and develop cooperative learning, working in pairs or small groups of students, thus facilitating communication, relationships, collaboration, and mutual support for solving problems or exploring new topics that lead to knowledge between students, mutual understanding, and acceptance.

Cooperative learning refers to a variety of teaching methods in which students work in small groups to help each other learn academic content. In the cooperating classrooms, students are expected to help each other, talk to each other, check their current level of knowledge, and fill in the gaps in understanding each other. The most common methods of cooperative learning are: Thinking Hats Method, Brainstorming, Gallery Tour, Mosaic, Role Playing, Method I Know / I Want to Know / I Found, Bunches, Lotus Technique, Cube Method, Think, Work in Pairs, communicate, Venn diagram, etc.

For example, among these methods we have chosen to briefly describe the "Mutual Teaching" Method, this being one of the methods of cooperative learning that can be used in online teaching.

\subsection{Description of the method Mutual teaching}

Mutual teaching is a method of cooperative learning through which students can experience the role of teacher and student, knowing that by teaching, you learn best. The number of students in the groups can be from four to seven, each of them having at hand the same text, divided, if necessary, in fragments, by the teacher. For each student to be able to play this role of great responsibility, it would be good for the number of fragments (paragraphs) of the text to determine the number of members of the working group.

Each student who plays this role must perform the following steps:

a) summarizes what she/he read;

b) asks a question about the text, to which others must answer; 
c) the question must refer to the essential problem of that passage, presented in explicit or implicit text;

d) clarifies things unclear to others;

e) makes predictions about the next passage and will see if it comes true during the next passage;

f) asks the others to read the next passage, specifying what it is.

\section{PRACTICAL SOLUTIONS TO MAKE COOPERATIVE LEARNING MORE EFFICIENT}

Depending on certain causes, for the efficiency of cooperative learning, the teacher will choose the relevant tactics. Thus, the teacher will have to encourage the student through accessible teaching tasks, moral support and positive feedback. The teacher will change the composition of the groups for a while and then propose interesting activities with common goals. Also, the teacher will be firm in the distribution of roles, functions and will insist on the observance of the rules initially established. In conclusion, cooperation is based on accomplishing tasks and is a form of superior interaction in learning, including collaboration.

As it has been found in the experience so far, online education has both positive and negative values.

The advantages of online learning:

a) students have access to education wherever they are;

b) student focus and individualization of learning;

c) transdisciplinary and interdisciplinary approach to the curriculum;

d) the possibility of storing / archiving documents (lessons, tests, portfolios, etc.) that highlight students' progress;

e) developing the digital skills of teachers and professors; quick access to information;

f) the focus is on practice, students are involved in finding answers and information;

g) the results obtained by the students are transmitted in a timely manner and accessible to both parents and students.

Limits of online learning:

a) there is a significant proportion of teachers who do not have digital skills;

b) the current curriculum allows to a very small extent the transposition into distance activities;

c) decreased students' external motivation for learning;

d) students from low-income families (or disadvantaged communities) are at a disadvantage; in most cases they do not have the necessary technology for online education (computer, internet);

e) there is a weak development of social skills, compared to face-to-face socialization;

f) lack of focus on lessons (often the student turns off the video camera or has other concerns during class);

g) the constant stress of parents because they have to help their children with their lessons.

In conclusion, the COVID-19 pandemic has accelerated the transition to this automation and artificial intelligence, which will reshape the future and the skills needed to adapt to new conditions.

\section{CONCLUSIONS}

Teachers are looking for solutions and developing their skills by finding new teaching strategies and methods, continuing to constantly improve in online teaching. Parents have had more than ever the opportunity to see how teachers and their children work on educational platforms. Students discovered their digital skills and improved their computer skills. 
Online instruction proves difficult in its practice in the classroom: guiding students by the teacher is a sophisticated process, the design of lessons must be structured in many ways, on different ways of asserting students. In the concrete conditions that our society makes available to the teaching process, teachers are aware on the one hand of the obvious virtues of the new approach (paradigm) in student education, and on the other hand of the difficulties (limits) of its application in the classroom, especially in the environment. online. So, without an adequate restructuring of the entire educational field (elaboration of programs, strategies and especially resources compatible with this type of learning), we can only witness the initiation of practices for activating students, on the background of orientation towards an online education.

Finally, we conclude that active participatory teaching strategies are complex ways of organizing and leading the training process based on the combination of methods, teaching aids and forms of grouping students, to achieve pedagogical objectives. They contribute to the optimization of the process of formation and formation of the students' personality, the teacher directing, leading, and continuously regulating the instructive action in the direction imposed by the finalities of the educational act. We believe that an assessment of digital skills / the use of ICT in the teachinglearning-assessment process of teachers should be carried out for each level of education, for adapting teaching content and activities to the requirements of online tools.

Depending on the results of the teachers' evaluation, mentoring services, specialized tutoring can be provided on different levels of difficulty and for levels of education to develop digital skills specific to online teaching. The current context has shown that the digitization of the educational system involves more than adapting to a technological context. Digital pedagogy is not a simple material in pdf format presented on the screen, but a much more complex approach. Educational platforms offer real support for teachers, but also for parents, so that the fundamental acquisitions of children are made naturally, through play and through an easy, accessible interaction.

Thus, we can conclude that online learning technology can play an important role in education, it can influence and generate in the future a new paradigm, as a component part of the educational system.

\section{REFERENCES}

Cerghit, I. (2008). Sisteme de instruire alternative şi complementare. Structuri stiluri şi strategii. Iasi: Polirom.

Cucoş, C. (2002). Pedagogie. Iași: Polirom.

Lewis, P. J. (2016). Brain friendly teaching-reducing student's cognitive load. Academic Radiology, 23(7),877-880.

Mcgee, P. (2014). Blended course design: where's the pedagogy? International Journal of 'Mobile and Blended Learning, 6.(1), 33-55.

Nicola, I. (2003). Tratat de pedagogie şcolară. Bucharest: Aramis.

Oprea, C. L. (2008). Strategii didactice interactive. Bucharest: Editura Didactică şi Pedagogică.

Shlomo, S., Sharan, Y. \& Lazarovitz, R. H. (1979). Effects of an Instructional Change Program on Teachers. British Journal of Teacher Education, 5,17-25.

Slavin, R. (1980). Cooperative learning. Review of Educational Research, 50, 315-342.

Stephenson, J. E., Brown, C. \& Griffin, D. K. (2008). Livrarea electronică a prelegerilor în mediul academic: O comparație empirică a trei stiluri de livrare. Computers and Education, 50, 640-651.

Tsay, M. \& Brady, M. (2010). A case study of cooperative learning and communication pedagogy: Does working in teams make a difference? Journal of the Scholarship of Teaching and Learning, 10(2).

Yong, J. (2005). Workflow-based e-learning platform. In Proceedings of the 9th International Conference on Computer Supported Cooperative Work in Design (CSCWD2005). 